\title{
Érase una vez una fábula que ni terminaba ni comenzaba ${ }^{1}$
}

\section{Carlos Monsiváis}

En 1964, Monterroso publica La oveja negra y demás fábulas, un libro que jamás culmina en (o desciende a) la moraleja. (¿De qué le sirven consejos abstractos a las situaciones que se explican por sí mismas?) El libro más famoso de su autor, con varias fábulas ya incorporadas a los libros de texto, La oveja negra impulsa y diversifica el enfoque satírico, en una cultura donde el moralismo ha perdido sus virtudes protagónicas. Monterroso declaró haber leído al James Thurber fabulista (Fables of our time, More fables of our time) luego de escribir La oveja negra. Pero sin duda y desde muy joven comparte con Thurber la sensación de alivio ante la eliminación de consejos y admoniciones y moralejas, grandes sobreentendidos de la literatura contemporánea. Así, sólo en una fábula de La oveja negra, hallo la moraleja, y ésta es nihilista y contraproducente; es en rigor una inmoraleja:

Si quieres triunfar contra Sansón, únete a los filisteos.

Si quieres triunfar sobre Dalila, únete a los filisteos.

Únete siempre a los filisteos.

[De "Sanson y los filisteos"]

Aunque no lo es del todo, sí puede definirse a La oveja negra como "bestiario humanizado", en la tradición de la Biblia (Yahvé concede voz a la burra de Balaam), de los latinos (Apuleyo), de los fabulistas exhaustivos (Esopo, Fedro, La Fontaine, Lessing, Dryden, Iriarte, Samaniego, Batres Montúfar), del portentoso episodio de los Yahoos en Viajes de Gulliver, y de la cima fantástica, Alicia en el país de las maravillas. A esta tradición ya responden tres grandes alegorías modernas: la anticlerical de Anatole France (La isla de los pingüinos), la antibelicista de Karel Capek ( $L a$ guerra con las salamandras) y la antistalinista de George Orwell (Animal Farm). Pero en La oveja negra también intervienen otros órdenes admirativos que constituyen la personal, intransferible tradición del autor: Cervantes. Mark Twain, Dostoievski, Joyce, Borges. No son influencias, sino asimilaciones, la diversidad en la unidad.

La fábula como suma de parejas: reticencia y entrega, recelo y confianza, crítica y elogio, entusiasmo y pesimismo El reino de la paradoja es circular, y la abstención generosa (nadie debe ser juez de su semejante) desemboca en la abstinencia crítica (nadie debe ser su semejante). En el intento de reconstruir o vislumbrar el universo destruido por la solemnidad, la tontería, la vanidad, la fuerza

\footnotetext{
${ }^{1}$ Fragmento extraído del libro de Carlos Monsiváis, Escribir, por ejemplo (De los escritores de la tradición). México: FCE, 2008.
} 
bruta, la opresión, Monterroso acude al microcosmos que solo los hábitos hollywoodenses del lector convertirán en macrocosmos. La realidad es deforme: el humor le restituye sus proporciones ideales. La realidad quiere hacerse pasar por la armonía celeste y la sátira denuncia su estratagema: es un juego apocalíptico sin Juicio Final.

En La oveja negra, Monterroso se acerca a lo escenificado con genio por Mack Sennett, Max Linder, Charles Chaplin, Buster Keaton y Harold Lloyd; lo sintetizado en la frase de Max Eastman: no es que el humor primitivo sea exagerado, sino que las exageraciones primitivas son humorísticas. Y el primitivismo de la conducta, el rugir del león, los saltos del mono, apuntan a la vez al primitivismo y la sofisticación del lector. (Lo que también advierte Monterroso: "Darwin debió proponer que el hombre descendería algún día del mono, y no que ya había descendido; pero como buen hombre de ciencia se hacía ilusiones".)

Antes que la condición humana, Monterroso controvierte el modo en que la condición humana se petrifica, distribuida en refranes, consejas, aforismos, frases hechas y experiencia paternal de sobremesa. Y en su indagación fabuladora, sin jamás hacerlo explícito, prueba que los depósitos de sabiduría ancestral son con frecuencia formaciones calcáreas. Por eso le informa a Margarita García Flores:

Decir que una cigarra debe trabajar como una hormiga ha sido una tontería repetida durante siglos. La cigarra no cambiará. En todo caso, la que debería cambiar sería la hormiga. Pero tampoco se puede caer siempre en este juego de poner las cosas al revés, de las paradojas fáciles, o de repetir la bella broma de que el cuervo no soltó el queso porque había leído a La Fontaine. Por desdicha, el cuervo siempre soltará el queso.

Según la observación de Baudelaire, lo cómico acentúa nuestra separación. Al reírnos de los demás insistimos en distanciarnos de aquello que convoca a nuestra risa. Pero el humor contemporáneo, al fin y al cabo fruto de la sociedad de masas, y urgido de la ambigüedad que es tributo al pluralismo, acentúa de igual modo la separación y la afinidad: somos, a un tiempo, diferentes e idénticos a lo que provoca nuestra risa, que es por lo mismo alivio y mortificación o, como diría algún condiscípulo de Eduardo Torres, bálsamo y llaga. La risa, forma de autocrítica: ¿quién se liberará de sí mismo mediante el recurso de burlarse de sí mismo? La sonrisa, forma de autorrestablecimiento: ¿quién se burlará de sí mismo sin liberarse en alguna medida? Se disuelven las fáciles distancias entre quien ríe o sonríe y la imagen satirizada. Sólo los que se involucran con el objeto satirizado trascienden la trampa esquemática de sentirse irónicos a costa de la inferioridad evidente.

Monterroso no extrae conclusiones de las conductas. Extrae conductas de aquello que la sociedad llama "conclusiones". Lo suyo es la reducción a lo concreto. Donde se ha visto la asimilación al sistema, Monterroso descubre el mono que quería ser escritor satírico. Donde suele captarse el reflejo o la presencia del hombre alienado, localiza a la rana que anhela ser una rana auténtica. 
Donde se situaría al chovinismo previsiblemente exaltado, aparece el grillo maestro que pondera -sobre lo emitido por las pobres gargantas- el sonido muy superior del frotamiento de las alas sobre los costados. En todo, lo fundamental es entender que también la ambigüedad es monolítica (y lo unívoco es ambiguo):

\section{MONÓLOGO DEL MAL}

Un día el Mal se encontró frente a frente con el Bien y estuvo a punto de tragárselo para acabar de una buena vez con aquella disputa ridícula; pero al verlo tan chico el Mal pensó:

"Esto no puede ser más que una emboscada; pues si ahora me trago al Bien, que se ve tan débil, la gente va a pensar que hice mal, y yo me encogeré tanto de vergüenza que el Bien no desperdiciará la oportunidad y me tragará a mí, con la diferencia de que entonces la gente pensará que él sí hizo bien, pues es difícil sacarla de sus moldes mentales consistentes en que lo que hace el Mal está mal y lo que hace el Bien está bien.”

Y así el Bien se salvó una vez más.

Teología de la deliberación. Optimismo del que sobrevive a su pesimismo. Pesimismo del que percibe el engaño montado por su optimismo. Y una certeza: el análisis más agudo de estas fábulas es su reproducción textual. Al no producir teoría, Monterroso reivindica a la tan denigrada anécdota y a través de ella acepta - tal como es - el universo de los seres y las cosas. Doble juego: desde la anécdota se niega la perfección y la coherencia del universo; a través de la paradoja, se aprecia la falta de poderes de la fábula:

Si no fuera malo, el mundo se regiría por las fábulas de Esopo; pero en tal caso desaparecería todo lo que hace interesante al mundo, como los ricos, los prejuicios raciales, el color de la ropa interior y la guerra; y el mundo sería entonces muy aburrido, porque no habría heridos para las sillas de ruedas, ni pobres a quienes ayudar, ni negros para trabajar en los muelles, ni gente bonita para la revista Vogue.

Así, lo mejor es acercarse a las fábulas buscando de qué reír [de La palabra mágica].

Si la risa no procede, que la sonrisa encauce la exégesis. Tómese "La oveja negra". Lo obvio es ver en esta fábula el epíteto eterno a beneficio de rebeldes e inconformes. Pero el texto no sólo admite ser leído como la revancha del Sistema (en cada etapa) contra el ser excepcional que lo afrenta. Puede tratarse también de la industrialización de los héroes, o de lo que a uno se le ocurra, y sin la multiplicidad de salidas interpretativas no hay fábula.

El espíritu cómico, y eso Monterroso lo entiende de manera extraordinaria, expresa las tensiones elementales y las soluciones de la naturaleza animada, la sofisticación animal que persiste en el hombre, el deleite del ser humano ante sus propios dones que -no sin dudas y recatos- lo tornan el rey o la reina de la creación a su alcance. El espíritu cómico también radica en la creencia gozosa en la autosuperación y la autorregeneración, dos expresiones de la imposibilidad de cambio. Y el espíritu cómico es el aviso de algo distinto a la razón y la locura: 
Había una vez un espejo de mano que cuando se quedaba solo y nadie se veía en él se sentía de lo peor, como que no existía. y quizá tenía razón; pero los otros espejos se burlaban de él, y cuando por las noches los guardaban en el mismo cajón del tocador dormían a pierna suelta satisfechos, ajenos a la preocupación del neurótico [“El espejo que no podía dormir"].

El dislocamiento lógico se extiende al límite, los caballos sólo concebirán a Dios bajo la forma de jinete, la gente abandonó la fe con tal de inmovilizar a las montañas, y Monterroso ha logrado la hazaña: oponerse a los lugares comunes, sin jamás reemplazarlos por otros.

III

\section{"El patrono muerto es menos feliz que el obrero vivo"}

El antecedente directo de Lo demás es silencio (La vida y obra de Eduardo Torres, de 1978) es el trabajo conjunto de Jorge Luis Borges y Adolfo Bioy Casares (Seis problemas para don Isidro Parodi, Crónica de H. Bustos Domecq). En América Latina, Borges y Bioy Casares inauguran la experimentación lujuriosa con la parodia, que en su caso elige como tema obsesivo el "idioma culto" latinoamericano que ha sido también modo de vida (la retórica, primera visión del mundo). Recreados por Borges y Bioy, el culteranismo, la ansiedad de edificar torres-de-Babel en cada observación y el uso complacido del humor involuntario hallan al mismo tiempo su exaltación quijotesca y su cumbre paródica. “¡Fatal e interesante idiosincrasia del hombre de letras!”, se dice en el prólogo de Seis problemas para don Isidro Parodi, y la frase introduce a la orgía de significaciones desprovistas de sentido. Detente, obviedad, eres tan bella... como en la dedicatoria de Crónicas de H. Bustos Domecq: "A esos tres grandes olvidados: Picasso, Joyce, Le Corbusier".

El Pickwick de Dickens, el Tartarín de Tarascón de Daudet, el Carlos Argentino Daneri de Borges, en Lo demás es silencio resulta ser el maestro Eduardo Torres, filósofo de San Blas, S. B., apóstol del tópico y Magallanes del lugar común, ansioso de repoblar la tierra con sus reflexiones. Desde la primera línea, la vida y la obra de don Eduardo solicitan el método de lectura que se desprende de la suspensión de la incredulidad, en este caso, la suspensión del afán indisciplinado de hilaridad. La clave de esta entrada a saco en las vivencias de la cultura occidental, tal y como se transmiten en la provincia, es la seriedad. Si no se toma en serio al maestro Torres, a su esposa y a sus parientes, no se entiende a todos los biógrafos de los grandes hombres de aquellos pueblos o ciudades en donde son primero los héroes y luego, mucho después, las hazañas.

En Lo demás es silencio están bajo sitio la gloria arcangélica de los Ateneos, la eficacia de la crítica autocelebratoria, la inercia de los lugares comunes que desplazan el aura de la sinceridad. Monterroso acosa a la obviedad, que Eduardo Torres describiría como las Scilla y Caribdis de la comunicación entre los hombres. La obviedad es el placer de descubrir América (como en esta frase), y la frase hecha es la reflexión profunda que recorre el mundo sin moverse de su sitio: “... rencillas mal entendidas y desestabilizadoras llamadas a saturarnos o a creer en un caos artificial ahí donde 
ese caos existe ya en forma por demás natural y amena”.

Ante la fila interminable de monumentos a los grandes que son obra de la fe y no de la demostración, Monterroso propone atenerse a lo que dicen. Nada es como antes, diría don Eduardo, porque, esto es lo más probable, antes ocurrió hace mucho tiempo, cuando, por lo mismo, nada era como ahora. Así, por ejemplo, la explicación del título Lo demás es silencio no se encuentra en el The rest is silence shakesperiano, sino en la tradición de los guiños pomposos, y su contexto real es la pedantería de los siempre informados a medias, los que para ser sabios necesitan deslumbrarse consigo mismos. La obviedad borra los contenidos originales, y ser el colonizador del Mediterráneo es aún posible, porque a estas alturas de la explosión demográfica nadie llega primero a lado alguno.

En las décadas de 1950 y 1960 se jugó en las reuniones literarias de México a la "Conversación Plana", que consistía en el intercambio de verdades palmarias, una tras otra en cascada, al punto de extinguir el diálogo. El juego era divertido hasta -diría Eduardo Torres- el momento en que dejaba de serlo, y uno comprobaba cuán fatigoso es hablar sólo de memoria. En Lo demás es silencio, a la "Conversación Plana" la perfecciona un intento ambicioso: explorar algunas de las infinitas zonas muertas de la conversación y de la escritura, examinar a fondo cómo la reiteración vuelve opaco o falso lo que fue cierto, observar alegremente cómo mucho de lo más prestigioso del idioma cultural latinoamericano devino carga funeraria o ya nació siéndolo.

Quizá, al goce de la furia paródica de Lo demás es silencio lo perturban las dos décadas invertidas por Monterroso en escribirlo. Durante ese tiempo se desvanecen formas y estilos invictos por siglo y medio en la tribuna, el púlpito y las academias, y desaparecen las intimidaciones de un lenguaje tan prosopopéyico como esta palabra. Ya los eruditos a la violeta y los culteranos se han visto acorralados y desplazados por el habla tecnocrática y las pretensiones científicas de la crítica literaria, los gobiernos abandonan el homenaje al humanismo, que desconocían, y se produce el canje de mitologías (out la grecolatina, in la de los medios electrónicos). Y para muchos lectores jóvenes la novedad de Lo demás es silencio radica en su "invención del pasado", la exasperación que resucita el lugar común y lo habilita como cultura cívica.

Sentencia Eduardo Torres: "Llevar un diario es un ejercicio y un placer espiritual que no practican ni gozan aquellos que no lo llevan”. Y añade: “Apuntar un pensamiento is a joy forever. Cuando el pensamiento no vale la pena debe apuntarse en un diario especial de pensamientos que no valen la pena". La serpiente se muerde la cola y, aislados y puestos de relieve, el lugar común y la obviedad resultan originales por inmutables, inquietantes porque siempre habitaron entre nosotros. Ya Stanislaw Jerzy Lec lo dijo: "No se puede estar ciego desde ningún punto de vista". 


\section{CUENTOS DE CARLOS MONTERROSO}

TE CONOZCO MASCARITA

El humor y la timidez generalmente se dan juntos. Tú no eres una excepción. El humor es una máscara y la timidez otra. No dejes que te quiten las dos al mismo tiempo.

\section{LA CUCARACHA SOÑADORA}

Era una vez una Cucaracha llamada Gregorio Samsa que soñaba que era una Cucaracha llamada Franz Kafka que soñaba que era un escritor que escribía acerca de un empleado llamado Gregorio Samsa que soñaba que era una Cucaracha.

\section{LA TORTUGA Y AQUILES}

Por fin, según el cable, la semana pasada la Tortuga llegó a la meta. En rueda de prensa declaró modestamente que siempre temió perder, pues su contrincante le pisó todo el tiempo los talones. En efecto, una diezmiltrillonésima de segundo después, como una flecha y maldiciendo a Zenón de Elea, llegó Aquiles.

\section{CABALLO IMAGINANDO A DIOS}

A pesar de lo que digan, la idea de un cielo habitado por Caballos y presidido por un Dios configura equina repugna al buen gusto y a la lógica más elemental, razonaba los otros días el Caballo. Todo el mundo sabe -continuaba en su razonamiento- que si los Caballos fuéramos capaces de imaginar a Dios lo imaginaríamos en forma de Jinete.

\section{HUMORISMO}

El humorismo es el realismo llevado a sus últimas consecuencias. Excepto mucha literatura humorística, todo lo que hace el hombre es risible o humorístico. En las guerras deja de serlo porque durante éstas el hombre deja de serlo. Dijo Eduardo Torres: "El hombre no se conforma con ser el animal más estúpido de la Creación; encima se permite el lujo de ser el único ridículo".

\section{LA OVEJA NEGRA}

En un lejano país existió hace muchos años una Oveja negra. Fue fusilada. Un siglo después, el rebaño arrepentido le levantó una estatua ecuestre que quedó muy bien en el parque. Así, en lo sucesivo, cada vez que aparecían ovejas negras eran rápidamente pasadas por las armas para que las futuras generaciones de ovejas comunes y corrientes pudieran ejercitarse también en la escultura.

\section{EPITAFIO ENCONTRADO EN EL CEMENTERIO MONTE PARNASO DE SAN BLAS} Escribió un drama: dijeron que se creía Shakespeare; Escribió una novela: dijeron que se creía Proust; Escribió un cuento: dijeron que se creía Chejov; Escribió una carta: dijeron que se creía Lord Chesterfield; Escribió un diario: dijeron que se creía Pavese; Escribió una despedida: dijeron que se creía Cervantes; Dejo de escribir: dijeron que se creía Rimbaud; Escribió un epitafio: 
dijeron que se creía difunto.

\section{LOS CUERVOS BIEN CRIADOS}

Cerca del Bosque de Chapultepec vivió hace tiempo un hombre que se enriqueció y se hizo famoso criando Cuervos para los mejores parques zoológicos del país y del mundo y los cuales resultaron tan excelentes que a la vuelta de algunas generaciones y a fuerza de buena voluntad y perseverancia ya no intentaban sacar los ojos a su criador sino que por lo contrario se especializaron en sacárselos a los mirones que sin falta y dando muestras del peor gusto repetían delante de ellos la vulgaridad de que no había que criar Cuervos porque le sacaban a uno los ojos.

\section{LA TELA DE PENÉLOPE, O QUIÉN ENGAÑA A QUIÉN}

Hace muchos años vivía en Grecia un hombre llamado Ulises (quien a pesar de ser bastante sabio era muy astuto), casado con Penélope, mujer bella y singularmente dotada cuyo único defecto era su desmedida afición a tejer, costumbre gracias a la cual pudo pasar sola largas temporadas. Dice la leyenda que en cada ocasión en que Ulises con su astucia observaba que a pesar de sus prohibiciones ella se disponía una vez más a iniciar uno de sus interminables tejidos, se le podía ver por las noches preparando a hurtadillas sus botas y una buena barca, hasta que sin decirle nada se iba a recorrer el mundo y a buscarse a sí mismo.

\section{LA FE Y LAS MONTAÑAS}

Al principio la Fe movía montañas sólo cuando era absolutamente necesario, con lo que el paisaje permanecía igual a sí mismo durante milenios. Pero cuando la Fe comenzó a propagarse y a la gente le pareció divertida la idea de mover montañas, éstas no hacían sino cambiar de sitio, y cada vez era más difícil encontrarlas en el lugar en que uno las había dejado la noche anterior; cosa que por supuesto creaba más dificultades que las que resolvía. La buena gente prefirió entonces abandonar la Fe y ahora las montañas permanecen por lo general en su sitio. Cuando en la carretera se produce un derrumbe bajo el cual mueren varios viajeros, es que alguien, muy lejano o inmediato, tuvo un ligerísimo atisbo de fe.

\section{DEJAR DE SER MONO}

El espíritu de investigación no tiene límites. En los Estados Unidos y en Europa han descubierto a últimas fechas que existe una especie de monos hispanoamericanos capaces de expresarse por escrito, réplicas quizá del mono diligente que a fuerza de teclear una máquina termina por escribir de nuevo, azarosamente, los sonetos de Shakespeare. Tal cosa, como es natural, llena estas buenas gentes de asombro, y no falta quien traduzca nuestros libros, ni, mucho menos, ociosos que los compren, como antes compraban las cabecitas reducidas de los jíbaros. Hace más de cuatro siglos que fray Bartolomé de las Casas pudo convencer a los europeos de que éramos humanos y de que teníamos un alma porque nos reíamos; ahora quieren convencerse de lo mismo porque escribimos. 


\section{LA RANA QUE QUERÍA SER UNA RANA AUTÉNTICA}

Había una vez una Rana que quería ser una Rana auténtica, y todos los días se esforzaba en ello. Al principio se compró un espejo en el que se miraba largamente buscando su ansiada autenticidad. Unas veces parecía encontrarla y otras no, según el humor de ese día o de la hora, hasta que se cansó de esto y guardó el espejo en un baúl. Por fin pensó que la única forma de conocer su propio valor estaba en la opinión de la gente, y comenzó a peinarse y a vestirse y a desvestirse (cuando no le quedaba otro recurso) para saber si los demás la aprobaban y reconocían que era una Rana auténtica. Un día observó que lo que más admiraban de ella era su cuerpo, especialmente sus piernas, de manera que se dedicó a hacer sentadillas y a saltar para tener unas ancas cada vez mejores, y sentía que todos la aplaudían. Y así seguía haciendo esfuerzos hasta que, dispuesta a cualquier cosa para lograr que la consideraran una Rana auténtica, se dejaba arrancar las ancas, y los otros se las comían, y ella todavía alcanzaba a oír con amargura cuando decían que qué buena Rana, que parecía Pollo.

\section{LA HONDA DE DAVID}

Había una vez un niño llamado David N., cuya puntería y habilidad en el manejo de la resortera despertaba tanta envidia y admiración en sus amigos de la vecindad y de la escuela, que veían en él y así lo comentaban entre ellos cuando sus padres no podían escucharlos un nuevo David. Pasó el tiempo. Cansado del tedioso tiro al blanco que practicaba disparando sus guijarros contra latas vacías o pedazos de botella, David descubrió que era mucho más divertido ejercer contra los pájaros la habilidad con que Dios lo había dotado, de modo que de ahí en adelante la emprendió con todos los que se ponían a su alcance, en especial contra Pardillos, Alondras, Ruiseñores y Jilgueros, cuyos cuerpecitos sangrantes caían suavemente sobre la hierba, con el corazón agitado aún por el susto y la violencia de la pedrada. David corría jubiloso hacia ellos y los enterraba cristianamente. Cuando los padres de David se enteraron de esta costumbre de su buen hijo se alarmaron mucho, le dijeron que qué era aquello, y afearon su conducta en términos tan ásperos y convincentes que, con lágrimas en los ojos, él reconoció su culpa, se arrepintió sincero y durante mucho tiempo se aplicó a disparar exclusivamente sobre los otros niños. Dedicado años después a la milicia, en la Segunda Guerra Mundial David fue ascendido a general y condecorado con las cruces más altas por matar él solo a treinta y seis hombres, y más tarde degradado y fusilado por dejar escapar con vida una Paloma mensajera del enemigo. 